\title{
Evaluation of a Mouthguard Customized Using the Occlusal Position during Maximal Grip Strength to Improve Sports Performance. A Case Report
}

\author{
Yoshiro Fujii \\ Shin-Kobe Dental Clinic, Chuou-Ku, Kobe, Japan \\ Email: shin-kobe-dentalclinic@s9.dion.ne.jp
}

How to cite this paper: Fujii, Y. (2019) Evaluation of a Mouthguard Customized Using the Occlusal Position during Maximal Grip Strength to Improve Sports Performance. A Case Report. Case Reports in Clinical Medicine, 8, 147-151.

https://doi.org/10.4236/crcm.2019.86017

Received: May 21, 2019

Accepted: June 15, 2019

Published: June 18, 2019

Copyright () 2019 by author(s) and Scientific Research Publishing Inc. This work is licensed under the Creative Commons Attribution International License (CC BY 4.0). http://creativecommons.org/licenses/by/4.0/

\begin{abstract}
Two customized mouthguards were developed for a 35-year-old male kickboxer. These were identical in thickness (the vertical dimension between the upper and lower jaws), the material, and similar in form (visible outline); however, one mouthguard was designed such that the horizontal jaw position was determined by the maximal grip strength obtained by the subject during the Bi-Digital O-Ring Test. Both mouthguards were satisfactory in terms of how they felt during wearing and breathing; however, the subject achieved higher kicking force, punching force, and back muscle strength while using the mouthguard with an optimized horizontal jaw position. These findings suggest that to enhance sports performance, it may be important to determine the optimal biting position. The grip strength obtained during the Bi-Digital O-Ring Test is a useful parameter for this assessment.
\end{abstract}

\section{Keywords}

Mouthguard, Sports Performance, Bi-Digital O-Ring Test

\section{Introduction}

Mouthguards are used for the prevention of traumatic dental injury and are important components of athletic equipment for participants of contact sports such as boxing, kickboxing, football, baseball, soccer, hockey, skateboarding, and gymnastics. In addition to the preventive role of mouthguards, there is some evidence that their use may influence athletic performance [1] [2] [3]. The purpose of this case report is to compare the effect of the occlusal position on sports 
performance.

\section{Case Presentation}

The subject was a 35-year-old male kickboxer. He had passed for 9 years after he debuted as a professional kickboxer at 26 years old but results weren't good recently. A peak of physical ability had also passed like his age, so he would have liked to play by a good mouthguard which makes a good biting situation to promote sports performance. A customized mouthguard had previously been developed for the subject. However, improvement of the sports performance like the rise of the muscle strength wasn't shared from this old mouthpiece. Therefore, a new mouthguard was developed that was comparable to the old one in some dimensions. Both mouthguards had an occlusal vertical dimension of approximately $3 \mathrm{~mm}$; however, the new mouthguard was designed with a horizontal biting position that was associated with the maximal grip strength achieved during a Bi-Digital O-Ring Test (Figure 1) [4] [5] [6].

To determine the horizontal jaw position, cotton blocks were placed on both molars such that the occlusal vertical dimension was raised by $3 \mathrm{~mm}$ at the anterior teeth; the subject was instructed to bite down, then move the lower jaw slightly while holding the cotton blocks between the upper and lower molars. Assessor administered the Bi-Digital O-Ring Test to identify the jaw position with the strongest grip. In this position, silicone rubber was poured into the space between the upper and lower jaws in order to record the occlusion. Plaster models of the upper and lower jaw were mounted using the silicone rubber to develop a customized mouthguard.

The new and old mouthguards (Figure 2, Figure 3) were used during a series of assessments that measured kicking force, punching force, and back muscle strength. As a result, kicking force, punching force, and back muscle strength were higher when using the new mouthguard $(327 \mathrm{~kg}, 204 \mathrm{~kg}$, and $92 \mathrm{~kg}$, respectively) than those when using the old mouth guard $(304 \mathrm{~kg}, 193 \mathrm{~kg}$, and $82 \mathrm{~kg}$, respectively); these differences reflect improvements of $7.6 \%, 6.3 \%$, and $12.2 \%$, respectively when using the new mouthguard.

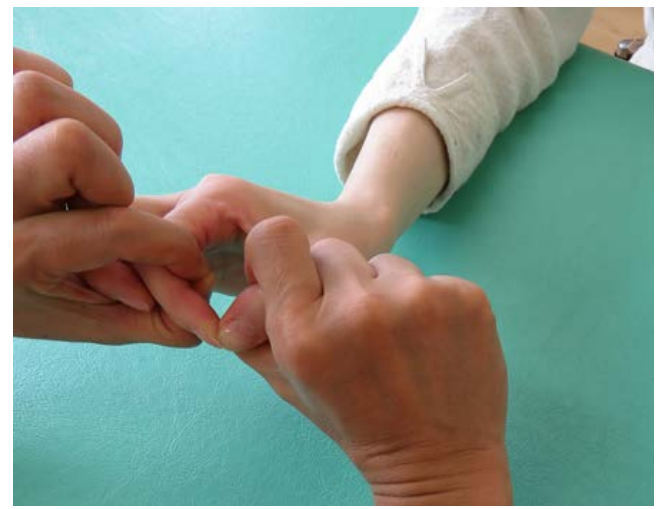

Figure 1. The Bi-Digital O-Ring Test was used to assess grip strength over a range of jaw biting positions. 


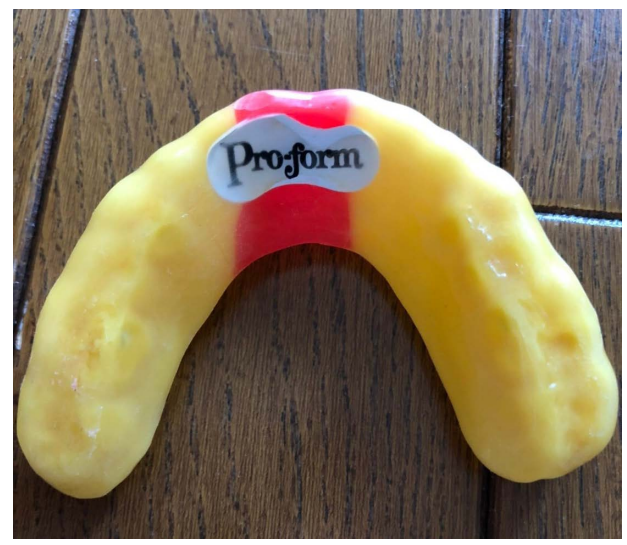

Figure 2. New mouthguad.

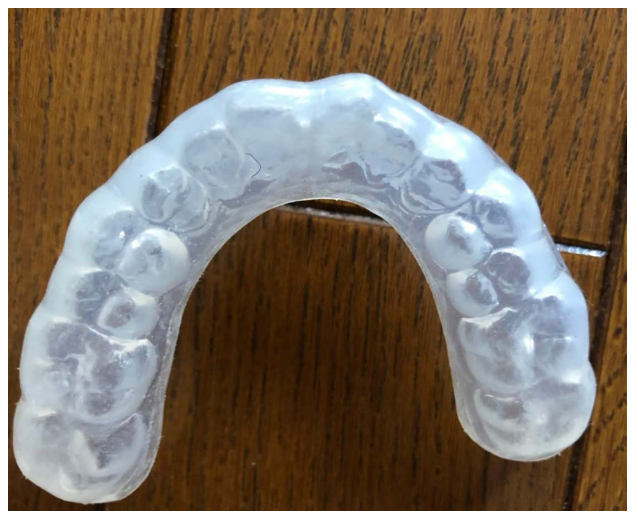

Figure 3. Old mouthguard. (Both outline form is similar. Vertical dimension between upper and lower jaw is the same, but horizontal biting position is different during placing them).

These assessments were video-recorded and can be observed on YouTube "Mouthguard for promoting sports performance"

https://www.youtube.com/watch?v=EfJkfHJmShw. In this video, the old and new mouthguards are referred to as the "normal" and "special" mouthguards respectively.

\section{Discussion}

Mouthguards are considered effective devices for buffering impacts that may cause dental and maxillofacial injuries during sports; however, their use alters the occlusal and mandibular positions. These changes have a substantial effect on full-body functioning [7]-[12] and may impact sports performance [13] [14] [15]. In this report, two customized mouthguards were compared. The old mouthguard raised the occlusal vertical dimension by approximately $3 \mathrm{~mm}$ at the anterior teeth; the new one provided the same occlusal vertical dimension but was designed with a horizontal occlusal position that was associated with the maximal grip strength achieved during the Bi-Digital O-Ring Test [4] [5] [6] [11] [12]. When using the new mouthguard, higher kicking force, punching force, and back muscle strength were achieved than those achieved when using 


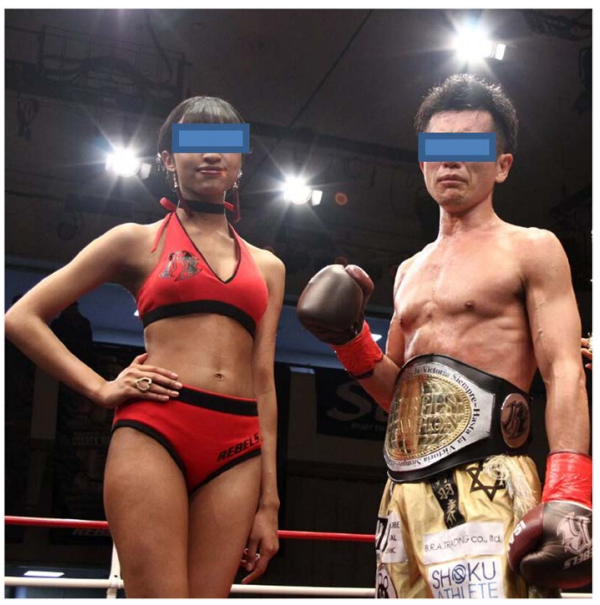

Figure 4. The subject won a championship event while using the new mouthguard in spite of older age as a sports player.

the old mouthguard. Following this study, the subject won a championship event while using the new mouth guard in spite of older age as this sports player (Figure 4). It is not clarified underlining mechanism why the sports performance has so improved by changing the horizontal occlusal position. However, anatomically, the trigeminal nerve existing around the oral cavity is the largest among the 12 pairs of cranial nerves. This fact suggests that quite much information is transmitted to a brain from a mouth. This is also clear from the experience that an author improved serious Alzheimer's disease by locating dentures [12]. In our study, it was useful to determine the optimal biting jaw position associated with better sports performance, which was represented by grip strength determined using the Bi-Digital O-Ring Test.

\section{Conclusion}

Mouthguards are essential equipment for athletes who take part in contact sports. In addition to preventing injury, mouthguards designed using the optimal occlusal position may improve sports performance. A useful measure to determine this is the maximal grip strength achieved during a Bi-Digital O-Ring Test.

\section{Acknowledgments}

The subject agreed for his case to be reported.

\section{Conflicts of Interest}

The author declares no conflicts of interest regarding the publication of this paper.

\section{References}

[1] Garner, D.P., Dudgeon, W.D., Scheett, T.P. and McDivitt, E.J. (2011) The Effects of Mouthpiece Use on Gas Exchange Parameters during Steady-State Exercise in College-Aged Men and Women. The Journal of the American Dental Association, 142, 1041-1047. https://doi.org/10.14219/jada.archive.2011.0325

[2] Keçeci, A.D., Cetin, C., Eroglu, E. and Baydar, M.L. (2005) Do Custom-Made Mouth Guards Have Negative Effects on Aerobic Performance Capacity of Athletes? 
Dental Traumatology: Official Publication of International Association for Dental Traumatology, 21, 276-280. https://doi.org/10.1111/j.1600-9657.2005.00354.x

[3] Duddy, F.A., Weissman, J., Lee Sr., R.A., Paranjpe, A., Johnson, J.D. and Cohenca, N. (2012) Influence of Different Types of Mouthguards on Strength and Performance of Collegiate Athletes: A Controlled-Randomized Trial. Dental Traumatology: Official Publication of International Association for Dental Traumatology, 28, 263-267. https://doi.org/10.1111/j.1600-9657.2011.01106.x

[4] Omura, Y. (1993) Bi-Digital O-Ring Test for Imaging and Diagnosis of Internal Organs of a Patient. US Patent No. 5188107.

http://academic.reed.edu/economics/parker/f11/354/pat/o-ring.pdf

[5] Bi-Digital O-Ring Test (BDORT). http://bdort.org/

[6] Fujii, Y. (2019) Dental Treatment with a Gold Alloy Cast Crown for Severe Lumbago. Open Journal of Stomatology, 9, 21-27.

https://doi.org/10.4236/ojst.2019.92003

[7] Watanabe, E.K., Yatani, H., Kuboki, T., Matsuka, Y., Terada, S., Orsini, M.G., et al. (1998) The Relationship between Signs and Symptoms of Temporomandibular Disorders and Bilateral Occlusal Contact Patterns during Lateral Excursions. Journal of Oral Rehabilitation, 25, 409-415.

https://doi.org/10.1046/j.1365-2842.1998.00262.x

[8] Karppinen, K., Eklund, S., Suoninen, E., Eskelin, M. and Kirveskari, P. (1999) Adjustment of Dental Occlusion in Treatment of Chronic Cervicobrachial Pain and Headache. Journal of Oral Rehabilitation, 26, 715-721.

https://doi.org/10.1046/j.1365-2842.1999.00448.x

[9] Sakaguchi, K., Mehta, N.R., Abdallah, E.F., Forgione, A.G., Hirayama, H., Kawasaki, T., et al. (2007) Examination of the Relationship between Mandibular Position and Body Posture. CRANIO: The Journal of Craniomandibular \& Sleep Practice, 25, 237-249. https://doi.org/10.1179/crn.2007.037

[10] Gangloff, P., Louis, J.P. and Perrin, P.P. (2000) Dental Occlusion Modifies Gaze and Posture Stabilization in Human Subjects. Neuroscience Letters, 293, 203-206. https://doi.org/10.1016/S0304-3940(00)01528-7

[11] Fujii, Y. (2015) Orthodontic Treatment to Improve Hip Joint Mobility and Balance. The Journal of Dentists, 3, 29-32. https://doi.org/10.12974/2311-8695.2015.03.01.5

[12] Fujii, Y. (2016) Two Cases of Severe Dementia Showing Dramatic Improvement after Denture Placement. Advances in Alzheimer's Disease, 5, 46-52. https://doi.org/10.4236/aad.2016.52004

[13] Gelb, H., Mehta, N.R. and Forgione, A.G. (1996) The Relationship between Jaw Posture and Muscular Strength in Sports Dentistry: A Reappraisal. CRANIO: The Journal of Craniomandibular \& Sleep Practice, 14, 320-325. https://doi.org/10.1080/08869634.1996.11745984

[14] Smith, S.D. (1978) Muscular Strength Correlated to Jaw Posture and the Temporomandibular Joint. The New York State Dental Journal, 44, 278-285.

[15] Al-Abbasi, H., Mehta, N.R., Forgione, A.G. and Clark, R.E. (1999) The Effect of Vertical Dimension and Mandibular Position on Isometric Strength of the Cervical Flexors. CRANIO: The Journal of Craniomandibular \& Sleep Practice, 17, 85-92. https://doi.org/10.1080/08869634.1999.11746082 